\title{
Intraportal Glucose Delivery Alters the Relationship Between Net Hepatic Glucose Uptake and the Insulin Concentration
}

Sharon R. Myers, Owen P. McGuinness, Doss W. Neal, and Alan D. Cherrington

Department of Molecular Physiology and Biophysics, Vanderbilt University School of Medicine, Nashville, Tennessee 37232-0615

\begin{abstract}
To examine the relationship between net hepatic glucose uptake (NHGU) and the insulin level and to determine the effects of portal glucose delivery on that relationship, NHGU was evaluated at three different insulin levels in seven $42-h$-fasted, conscious dogs during peripheral glucose delivery and during a combination of peripheral and portal glucose delivery. During peripheral glucose delivery, at arterial blood glucose levels of $\sim 175 \mathrm{mg} / \mathrm{dl}$ and insulin levels reaching the liver of $51 \pm 2$, $92 \pm 6$, and $191 \pm 6 \mu \mathrm{U} / \mathrm{ml}$, respectively, NHGUs were $0.55 \pm 0.30,1.52 \pm 0.44$, and $3.04 \pm 0.79 \mathrm{mg} / \mathrm{kg}$ per $\mathrm{min}$, respectively. At hepatic glucose loads comparable to those achieved during peripheral glucose delivery and inflowing insulin levels of $50 \pm 4,96 \pm 5$, and $170 \pm 8 \mu \mathrm{U}$ per $\mathrm{ml}$, respectively, NHGUs were $1.96 \pm 0.48,3.67 \pm 0.68$, and $5.52 \pm 0.92 \mathrm{mg} / \mathrm{kg}$ per $\mathrm{min}$ when a portion of the glucose load was delivered directly into the portal vein. The results of these studies thus indicate that net hepatic glucose uptake is dependent on both the plasma insulin level and the route of glucose delivery and that under physiological conditions the "portal" signal is at least as important as insulin in the determination of net hepatic glucose uptake. (J. Clin. Invest. 1991. 87:930-939.) Key words: hyperinsulinemia $\bullet$ hyperglycemia $\bullet$ carbohydrate $\bullet$ metabolism • dog
\end{abstract}

\section{Introduction}

Under euglycemic conditions, the ability of insulin to inhibit hepatic glucose production has been demonstrated repeatedly in both man and $\operatorname{dog}(1-10)$. The role of insulin in promoting net hepatic glucose uptake in response to the hyperglycemia resulting from a glucose load is less clear. Although studies

Address correspondence and reprint requests to A. D. Cherrington, Ph.D., Department of Molecular Physiology \& Biophysics, Vanderbilt University School of Medicine, Nashville, TN 37232-0615. Dr. Myers' present address is Lilly Research Laboratories, Eli Lilly and Co., Indianapolis, IN 46285.

Received for publication 27 February 1990 and in revised form 9 October 1990

1. Abbreviations used in this paper: $\mathrm{ABF}, \mathrm{HBF}$, and $\mathrm{PBF}$, arterial, hepatic, and portal blood flow; G, glucose; GIR, intraportal glucose infusion rate; GL, glucose load; GUG, glucose uptake by gastrointestinal

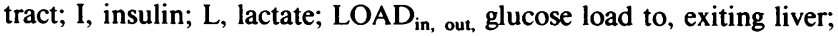
HFXE, hepatic fractional extraction of glucose; NHGB, NHLB, net hepatic glucose, lactate balance; NHGU, net hepatic glucose uptake; PAH, para-aminohippurate; PCA, perchloric acid; $\mathrm{P}_{\mathrm{e}, \mathrm{o}}$, protocol 1,2.

J. Clin. Invest.

(c) The American Society for Clinical Investigation, Inc.

0021-9738/91/03/0930/10 \$2.00

Volume 87, March 1991, 930-939 carried out in both species have demonstrated the importance of insulin in the promotion of glucose uptake by the liver (917), the actual dose-response relationship between net hepatic glucose uptake and the insulin level has yet to be defined.

Experiments carried out in man have suggested that insulin may play only a permissive role in the determination of splanchnic glucose uptake. In a study by DeFronzo et al. (5), in which the plasma glucose and insulin levels were raised via peripheral intravenous infusion to $223 \mathrm{mg} / \mathrm{dl}$ and $55 \mu \mathrm{U} / \mathrm{ml}$, respectively, net splanchnic glucose uptake was $1.0 \mathrm{mg} / \mathrm{kg}$ per $\mathrm{min}$. The rate of glucose uptake did not change appreciably when the arterial insulin level was raised further to $191 \mu \mathrm{U} / \mathrm{ml}$. Similar results were obtained by Ferrannini et al. (6). Studies carried out in the conscious dog have examined net hepatic glucose uptake at only one insulin level. In response to peripheral glucose delivery and a fourfold elevation in the plasma insulin level (17) glucose uptake by the canine liver was 2.8 $\mathrm{mg} / \mathrm{kg}$ per min.

In addition to insulin and glucose, recent studies carried out in both man and the dog have led to the proposal that a third regulator of net hepatic glucose uptake, a factor associated with intraportal glucose delivery, is involved. DeFronzo et al. (5) reported a sixfold increase in net splanchnic glucose uptake (from 1.0 to $5.9 \mathrm{mg} / \mathrm{kg}$ per min) when an oral glucose load was added to a peripheral glucose infusion in man. Ferrannini et al. (6), also working in man, observed a 3.4-fold increase in net splanchnic glucose uptake (from 1.2 to $4.1 \mathrm{mg}$ / $\mathrm{kg}$ per $\mathrm{min}$ ) when glucose was ingested rather than infused into a peripheral vein. Ishida et al. (15) working in dog found that the increase in uptake of glucose by the liver during absorption of an oral glucose load could be mimicked by infusion of glucose directly into the portal vein $(7.3$ and $6.9 \mathrm{mg} / \mathrm{kg}$ per min during oral and intraportal glucose delivery, respectively), and reported that intraportal glucose delivery in dog increased net liver glucose uptake sixfold over that observed during a peripheral infusion of glucose. Barrett et al. (10) also found equivalent uptake of glucose by the liver in the dog during oral and intraportal glucose delivery $(4.2$ and $5.5 \mathrm{mg} / \mathrm{kg}$ per min, respectively) and noted that this increase in net hepatic glucose uptake was greater than that observed during peripheral glucose administration $(2.8 \mathrm{mg} / \mathrm{kg}$ per $\mathrm{min})$. This was the case even though portal vein insulin concentrations in the peripheral glucose studies were 2.2-fold greater than those in the oral glucose experiments. Studies by Adkins et al. $(16,17)$ demonstrated that in the dog, net glucose uptake by the liver in response to hyperglycemia was significantly greater in the presence of a "portal" signal both in the absence of a rise in insulin and during moderate elevations in the plasma insulin level.

The aims of this study were to examine the role of physiologic changes in insulin in the regulation of net hepatic glucose uptake, and to determine if the influence of intraportal glucose delivery on net liver glucose uptake is maintained over a physiological range of elevations in insulin. 


\section{Methods}

Animals and surgical procedures. Experiments were carried out on seven mongrel dogs (16-28 kg) of either sex that had been fed a meat and chow diet (31\% protein, $52 \%$ carbohydrate, $11 \%$ fat, and $6 \%$ fiber based on dry weight; Kal Kan meat; Kal Kan Foods, Inc., Vernon, CA and Wayne Dog Chow; Allied Mills, Inc., Chicago, IL) once daily for 2 wk and that had been without food for $42 \mathrm{~h}$. $16 \mathrm{~d}$ before the experiment, a laparotomy was performed under general anesthesia (sodium pentobarbitol, $25 \mathrm{mg} / \mathrm{kg}$ ) during which time Silastic catheters were inserted into a splenic vein, a jejunal vein, the portal vein, and the left common hepatic vein. The gastroduodenal vein was ligated and Doppler flow probes (Instrumentation Development Laboratories, Baylor College of Medicine, Houston, TX) were positioned around the portal vein and the common hepatic artery. The tips of the splenic and jejunal catheters were placed $1 \mathrm{~cm}$ beyond the first site of coalescence of the catheterized vein with another vessel. The tip of the portal vein catheter was placed $2 \mathrm{~cm}$ distal to the point at which the vessel enters the liver, and the tip of the hepatic vein catheter was placed $1 \mathrm{~cm}$ inside the left common hepatic vein. A fifth catheter was inserted into the left femoral artery after a cut-down in the left inguinal region. After insertion the catheters were filled with saline-containing heparin $(200 \mathrm{U} / \mathrm{ml}$; Abbott Laboratories, North Chicago, IL), and their free ends were knotted. The free ends of the catheters and the leads to the flow probes were then placed in subcutaneous pockets to allow complete closure of the incisions. Penicillin G (500,000 U i.m.; Pfizer, New York, NY) was administered postoperatively, and ampicillin $(1,000 \mathrm{mg}$ p.o.; E.R. Squibb \& Sons, Inc., Princeton, NJ) was given on each of the first two postoperative days. $2 \mathrm{wk}$ after surgery blood was drawn to determine the leukocyte count and the hematocrit of the animal. Only animals that had $(a)$ a leukocyte count below $18,000 / \mathrm{mm}^{3},(b)$ an hematocrit above $38 \%,(c)$ normal stools, and $(d)$ a good appetite (consuming all of the daily ration) were used.

On the day of the experiment, the free ends of the catheters and the flow probe leads were exteriorized from the subcutaneous pockets through small incisions made under local anesthesia (2\% Lidocaine). The contents of each catheter were aspirated, and the catheters were flushed with saline. Catheters in the splenic and jejunal veins were used for the intraportal infusion of insulin, glucagon (Eli Lilly and Co., Indianapolis, IN), and glucose. Catheters in the portal vein, hepatic vein, and femoral artery were used for blood sampling. Angiocaths (20gauge; Deseret Medical, Inc., Becton Dickinson \& Co., Sandy, UT) were inserted percutaneously into the left cephalic vein for the continuous infusion of indocyanine green dye (Hynson, Westcott and Dunning, Baltimore, MD), into the right cephalic vein for the peripheral infusion of glucose, and into a saphenous vein for the peripheral infusion of para-aminohippurate (PAH) ${ }^{1}$, somatostatin (Bachem, Inc., Torrance, CA), and potassium chloride. The dog rested quietly in a Pavlov harness for 20-30 min before the beginning of the experiment and remained there for the duration of the study.

At the conclusion of the experiment, the animal was anesthetized, the catheters were flushed with fresh saline and filled with dilute heparin $(200 \mathrm{U} / \mathrm{ml})$, the free ends of the catheters were knotted and placed subcutaneously as described earlier, and the dog was treated with antibiotics as before. The leukocyte count and the hematocrit were determined again 2-3 d before the day of the second experiment. Only dogs which met the criteria described previously were restudied.

Experimental design. Each experiment in the two protocols consisted of an 80-min dye equilibration period (0-80 $\mathrm{min})$, a $40-\mathrm{min}$ control period (80-120 min, period I), and three 90-min test periods (120-210 min, period II; $210-300 \mathrm{~min}$, period III; 300-390 min, period IV). Each test period consisted of a 60 -min equilibration period and a 30-min sampling period during which experimental values were determined. A constant infusion of indocyanine green dye $\left(0.1 \mathrm{mg} / \mathrm{m}^{2}\right.$ per min) was begun at $0 \mathrm{~min}$. In protocol $1\left(P_{\mathrm{e}}\right)$, a peripheral infusion of somatostatin $(0.8 \mu \mathrm{g} / \mathrm{kg}$ per $\mathrm{min})$ and intraportal infusions of insulin $(0.6 \mathrm{mU} / \mathrm{kg}$ per $\mathrm{min})$ and replacement glucagon $(0.5 \mathrm{ng} / \mathrm{kg}$ per $\mathrm{min})$ were started at the beginning of period II. To fill the rapidly equilibrat- ing glucose distribution space and to quickly raise the blood glucose concentration to the target level, a peripheral glucose infusion (D50) of $\sim 30 \mathrm{mg} / \mathrm{kg} / \mathrm{min}$ was also begun at this time. The glucose infusion rate was rapidly decreased in increments of $5 \mathrm{mg} / \mathrm{kg}$ per min over a 10 -min period down to a rate of $\sim 4-5 \mathrm{mg} / \mathrm{kg}$ per min. The glucose infusion rate was then adjusted as needed to maintain a constant plasma glucose level that would result in an approximate doubling of the hepatic glucose load. The insulin infusion rate was increased to $1.2 \mathrm{mU} / \mathrm{kg}$ per min at the beginning of period III and the peripheral glucose infusion rate was increased as needed to maintain the arterial blood glucose concentration at the level established during period II. The insulin infusion rate was increased to $2.4 \mathrm{mU} / \mathrm{kg} / \mathrm{min}$ at the beginning of period IV, and again the peripheral glucose infusion rate was adjusted so as to maintain the arterial blood glucose concentration at a constant level. A peripheral infusion of $\mathrm{KCl}(6 \mu \mathrm{Eq} / \mathrm{kg} / \mathrm{min})$ was also begun at time 300 to prevent insulin-induced hypokalemia.

In protocol $2\left(\mathrm{P}_{0}\right)$, a constant peripheral infusion of PAH $(0.4 \mathrm{mg} /$ $\mathrm{kg} / \mathrm{min}$ ) was begun at $0 \mathrm{~min}$. At the beginning of period II, hormone (insulin, glucagon, somatostatin) infusions were begun as in protocol I; a 10-min peripheral glucose (D50) prime (glucose infusion rate of $\sim 25$ $\mathrm{mg} / \mathrm{kg}$ per min, decreased in increments of $5 \mathrm{mg} / \mathrm{kg}$ per min over a 10-min period down to $0 \mathrm{mg} / \mathrm{kg}$ per $\mathrm{min}$ ) and an intraportal glucose/ PAH infusion (PAH mixed with D20 in such a way that the PAH infusion rate was $\sim 0.4 \mathrm{mg} / \mathrm{kg}$ per min and the intraportal glucose infusion rate was $\sim 4-5 \mathrm{mg} / \mathrm{kg}$ per $\mathrm{min}$ ) were initiated to rapidly raise the blood glucose level so that the hepatic glucose load approximated that achieved in the corresponding period of protocol 1 . The peripheral PAH infusion was discontinued at the beginning of period II. The blood glucose level was maintained constant for the remainder of the period through slight adjustments in the intraportal glucose infusion rate. The insulin infusion rate was increased at the beginning of period III in the same manner as it was in the corresponding period of protocol 1 , and a peripheral glucose (D50) infusion was started to maintain a constant blood glucose level without altering the rate of portal glucose delivery (arterial-portal glucose gradient) established during period II. The insulin infusion rate was raised again and a peripheral infusion of $\mathrm{KCl}(6 \mu \mathrm{Eq} / \mathrm{kg}$ per min) was begun at the beginning of period IV as in the other protocol, and the peripheral glucose infusion rate was adjusted to maintain a constant blood glucose concentration.

Each of seven dogs was studied using both protocols, the experiments being carried out in a randomized fashion, 1 wk apart.

Femoral artery, portal vein, and hepatic vein samples were taken every 20 min during period I and every 15 min during the last $30 \mathrm{~min}$ of periods II, III, and IV, giving three hepatic balance estimates for each time period. The collection and immediate processing of blood samples have been described previously (18). The arterial and portal vein blood samples were collected simultaneously, and the hepatic vein sample was collected $\sim 30 \mathrm{~s}$ later to help compensate for transit time through the liver (19).

Analytical procedures. Six determinations of the glucose concentration were made on each plasma sample using the glucose-oxidase method (20) in a Beckman glucose analyzer (Beckman Instruments, Inc., Fullerton, CA). Four blood glucose and two lactate determinations were made on PCA (perchloric acid) extracts of blood using the Technicon Autoanalyzer II (Technicon Instruments Corp., Tarrytown, NY) according to the method of Lloyd et al. (21). Duplicate blood PAH levels were determined on PCA extracts of blood using an adaptation of the method developed by Brun (22). Immunoreactive insulin was measured using a double antibody procedure (23), and immunoreactive glucagon concentrations were determined using the $30 \mathrm{~K}$ antiserum of Unger according to the method of Aguilar-Parada et al. (24) after collection of plasma into Trasylol (500 KIU Trasylol/ml plasma; FBA Pharmaceuticals, New York). Indocyanine green used in the estimation of hepatic blood flow was measured spectrophotometrically at 805 $\mathrm{nm}$ according to the method of Leevy et al. (25). Doppler-determined blood flow was obtained using an ultrasonic, range-gated, pulsed Doppler flow meter designed by Hartley et al. (26) and described by Hartley et al. (26) and Ishida et al. (27). 
Calculations. Due to the large potential error that incomplete mixing of the intraportally-delivered glucose within the portal vein could introduce to the results (16), a method was devised to detect gross errors in mixing. PAH, a substance not extracted by the liver (this was verified using the peripheral PAH infusion), was mixed with the intraportal glucose infusate, and the recovery of PAH across the liver was measured (recovery $\left.=\mathrm{HBF} \times\left(\mathrm{PAH}_{\mathrm{H}}-\mathrm{PAH}_{\mathrm{A}}\right)\right)$ where $\mathrm{HBF}$ represents total hepatic blood flow and $\mathrm{PAH}_{\mathrm{A}}$ and $\mathrm{PAH}_{\mathrm{H}}$ represent arterial and hepatic vein blood PAH concentrations, respectively. The ratio between the recovery of intraportally-infused PAH and the actual intraportal PAH infusion rate was then calculated and used as an index of mixing of the intraportal infusate with the blood by the time the latter exits the liver. Because of the magnitude of the coefficient of variation of the method for assessing PAH balance, samples could be considered statistically "unmixed" (i.e., greater than $95 \%$ confidence that mixing did not occur) if hepatic recovery of intraportally-infused PAH was $40 \%$ greater or less than the actual amount of PAH infused. In 19 experiments in which this approach has been employed to evaluate the mixing of glucose in the portal and hepatic blood the infusate failed to mix with the blood only $14 \%$ of the time. More importantly, mixing errors when they do occur are random. Accordingly, the overall recovery of infused PAH on the downstream side of the liver in the present set of experiments was $100 \pm 11 \%$.

In a similar manner, substituting $\mathrm{PAH}_{\mathrm{P}}$ for $\mathrm{PAH}_{\mathrm{H}}$ in the recovery equation allows for the assessment of mixing of the infusate in the hepatic portal system. In the same set of 19 experiments, poor recovery of PAH in the hepatic portal system occurred more frequently (38\% of the time) but was again random in nature. To circumvent any potential problems arising from incomplete mixing, particularly in the portal vein, hepatic glucose balance was calculated both directly (using the portal vein glucose concentration) and indirectly (using the measured intraportal glucose infusion rate and an estimate of the uptake of glucose by the gastrointestinal tract).

Because the canine red cell itself can act as a glucose carrier (28), the most accurate assessment of hepatic glucose balance is obtained using blood glucose values. On the other hand, measurement of whole blood glucose values is less accurate than plasma glucose measurement because it requires a PCA deproteinization step. To lessen the error introduced into the hepatic glucose balance calculation by the use of whole blood glucose values, an attempt was made to determine the arterio-venous (A-V) difference as accurately as possible using plasma glucose and then to correct that value to whole blood glucose using a blood glucose/plasma glucose ratio. In each experiment the ratio apparent in each vessel (artery, portal, hepatic) during each of the four periods (I, II, III, IV) was computed and used to compute the blood glucose A-V difference at each site during each period. Net hepatic glucose balance was calculated using whole blood glucose values directly, as well as using plasma glucose differences corrected to blood glucose differences using the blood/plasma glucose ratio. With the exception of Table VII all glucose balance and load data contained in the mean data base were calculated using plasma glucose differences corrected to blood glucose differences.

In protocol $\mathrm{I}$, the load of glucose to the gastrointestinal tract (GL $=\mathrm{PBF} \times G_{\mathrm{A}}$, where $G_{\mathrm{A}}$ represents the arterial blood glucose concentration and $\mathrm{PBF}$ equals portal vein blood flow) and the uptake of glucose by the gastrointestinal tract $\left(\mathrm{GUG}=\mathrm{PBF} \times\left(G_{\mathrm{A}}-G_{\mathrm{P}}\right)\right.$, where $G_{\mathrm{P}}$ represents the portal vein blood glucose concentration) were calculated, and the relationship between the two values was determined $\left(G U G=\left[0.423 \times\left(G_{T} / G_{C}\right)+0.430\right] \times G U G_{C}, T\right.$ and $C$ representing time and control period values, respectively). This relationship was then used for both protocols in the indirect calculation of the hepatic glucose load.

LOAD $_{\text {in }}$ was calculated, as in previous studies $(16,17)$, using two different methods: $(a)$ indirectly according to the equation $\operatorname{LOAD}_{\text {in }}$ $=\left(G_{\mathrm{A}} \times \mathrm{HBF}\right)+\mathrm{GIR}_{\mathrm{Po}_{\mathrm{o}}}$ is the intraportal glucose infusion rate and $(b)$ directly as $\mathrm{LOAD}_{\text {in }}=\left[\left(G_{\mathrm{A}} \times \mathrm{ABF}\right)+\left(G_{\mathrm{P}} \times \mathrm{PBF}\right)\right]$, where $\mathrm{ABF}$ represents hepatic arterial blood flow. The load of glucose exiting the liver $\left(\mathrm{LOAD}_{\text {out }}\right)$ was calculated using the equation $\mathrm{LOAD}_{\text {out }}=G_{\mathrm{H}} \times \mathrm{HBF}$ where $G_{\mathrm{H}}$ represents the hepatic vein blood glucose concentration. Net hepatic glucose balance (NHGB) was determined both indirectly $\left(\mathrm{NHGB}_{\text {ind }}\right)$ and directly $\left(\mathrm{NHGB}_{\text {dir }}\right)$ as the difference between $\mathrm{LOAD}_{\text {out }}$ and the indirectly or directly calculated $\mathrm{LOAD}_{\text {in }}$, with positive values representing net output of glucose by the liver and negative values representing net liver glucose uptake. With the exception of Table $V$ all glucose balance and load data contained in the mean data base were calculated using the indirect approach.

Hepatic fractional extraction of glucose was calculated using the indirectly calculated $\mathrm{LOAD}_{\text {in }}$ according to the following formula: extraction $=\left(\mathrm{LOAD}_{\text {in }}-\mathrm{LOAD}_{\text {out }}\right) / \mathrm{LOAD}_{\text {in }} \times 100$.

Net hepatic lactate balance (NHLB) was calculated using the equation NHLB $=\left(L_{\mathbf{H}} \times \mathrm{HBF}\right)-\left[\left(L_{\mathrm{A}} \times \mathrm{ABF}\right)+\left(L_{\mathrm{P}} \times \mathrm{PBF}\right)\right]$, where $L_{\mathrm{H}}$, $L_{\mathrm{A}}$, and $L_{\mathrm{P}}$ are the concentrations of blood lactate in the hepatic vein, artery and portal vein, respectively. As with NHGB, calculation of NHLB in this manner gives positive values for net lactate output by the liver and negative values for net hepatic lactate uptake. Multiplication of NHLB by $0.09 \mathrm{mg}$ glucose $/ \mu \mathrm{mol}$ lactate was used to convert NHLB to glucose equivalents. Net hepatic balance of glucose equivalents was calculated as the sum of NHLB and NHGB $_{\text {ind }}$

Hepatic fractional extraction of insulin was calculated according to the equation: $\left(\left[\left(I_{\mathrm{A}} \times \mathrm{ABF}\right)+\left(I_{\mathrm{P}} \times \mathrm{PBF}\right)\right]-\left(I_{\mathrm{H}} \times \mathrm{HBF}\right)\right) /\left[\left(I_{\mathrm{A}} \times \mathrm{ABF}\right)\right.$ $\left.+\left(I_{P} \times P B F\right)\right]$, where $I_{A}, I_{P}$, and $I_{H}$ represent insulin concentrations in the artery, portal vein, and hepatic vein, respectively.

The average concentration of a substance entering the liver $\left(S_{\text {ave }}\right.$; calculated for glucose, insulin, and glucagon) was determined as follows: $S_{\text {ave }}=\left[\left(S_{\mathrm{A}} \times \mathrm{ABF}\right)+\left(S_{\mathrm{P}} \times \mathrm{PBF}\right)\right] / \mathrm{HBF}$, where $S_{\mathrm{A}}$ and $S_{\mathrm{P}}$ are the concentration of the substance in the artery and the portal vein, respectively.

Peripheral uptake of glucose (PUG) was calculated as the difference between the total glucose infusion rate $\left(\mathrm{GIR}_{\mathrm{T}}\right)$ and $\mathrm{NHGB}_{\text {ind }}$. Peripheral glucose clearance was calculated as the ratio between PUG and the plasma glucose concentration.

Because the Doppler method of blood flow measurement was begun after the initiation of these protocols, Doppler-determined blood flow values were available in only four of the dogs studied. In these animals Doppler determined and indocyanine green blood flow values were used in data calculation (see Table VI for comparison) although only the Doppler determined data were included in the $n=7$ data base. For calculations from the remaining three experiments, indocyaninegreen-determined blood flow data alone were used, and the distribution of blood flow between the hepatic artery and the portal vein was assumed to be 28 and $72 \%$, respectively (29), so that in calculations from these experiments, $\mathrm{ABF}=0.28 \times \mathrm{HBF}$, and $\mathrm{PBF}=0.72 \times \mathrm{HBF}$. This is the approach we have used previously and in fact the average arterial/portal flow distribution evident from the Doppler data during glucose infusion in the present experiments $(26 \%$ artery and $74 \%$ portal) was indistinguishable from the distribution previously assumed based on the literature.

The reported data represent the means \pm SEM of the average steadystate values (last $30 \mathrm{~min}$ of each period). Statistical significance $(P$ $<0.05$ ) was determined using the paired Student's $t$ test (30).

\section{Results}

Hormone values and glucose infusion rates. The average concentrations of insulin reaching the liver were $34 \pm 1,51 \pm 2$, $92 \pm 6$, and $191 \pm 11 \mu \mathrm{U} / \mathrm{ml}$ in periods I-IV of $P_{e}$ and $27 \pm 3$, $50 \pm 4,96 \pm 5$, and $170 \pm 8 \mu \mathrm{U} / \mathrm{ml}$ in the same periods of $P_{0}$ (Table I). Hepatic fractional extraction of insulin increased slightly during the first insulin step of protocol 1 and in the second step of protocol 2 but was similar between the corresponding periods of the two protocols.

The average concentration of glucagon reaching the liver (Table II) decreased slightly by the end of the experiment in both protocols but was not significantly different between 
Table I. Insulin Concentrations in the Artery, Portal Vein, and Hepatic Vein

\begin{tabular}{|c|c|c|c|c|c|}
\hline & \multicolumn{4}{|c|}{ Insulin concentration } & \multirow[b]{2}{*}{$\begin{array}{l}\text { Hepatic fractional } \\
\text { extraction of insulin }\end{array}$} \\
\hline & Artery & $\begin{array}{l}\text { Portal } \\
\text { vein }\end{array}$ & $\begin{array}{l}\text { Hepatic } \\
\text { vein }\end{array}$ & INS $_{\text {ave }}$ & \\
\hline & \multicolumn{4}{|c|}{$\mu U / m l$} & $\%$ \\
\hline \multicolumn{6}{|c|}{ Protocol $1\left(P_{e}\right)$} \\
\hline Period I & $15 \pm 2$ & $39 \pm 2$ & $19 \pm 4$ & $34 \pm 1$ & $41 \pm 4$ \\
\hline Period II & $18 \pm 2$ & $62 \pm 3^{\ddagger}$ & $21 \pm 2$ & $51 \pm 2^{\ddagger}$ & $57 \pm 2^{\ddagger}$ \\
\hline Period III & $36 \pm 2^{\ddagger}$ & $112 \pm 9^{\ddagger}$ & $43 \pm 5^{\ddagger}$ & $92 \pm 6^{\ddagger}$ & $48 \pm 5$ \\
\hline Period IV & $92 \pm 8^{\ddagger}$ & $230 \pm 13^{\ddagger}$ & $94 \pm 12^{\ddagger}$ & $191 \pm 11^{\ddagger}$ & $46 \pm 3$ \\
\hline \multicolumn{6}{|c|}{ Protocol $2\left(P_{0}\right)$} \\
\hline Period I & $12 \pm 2^{*}$ & $32 \pm 4^{*}$ & $15 \pm 2$ & $27 \pm 3^{*}$ & $43 \pm 3$ \\
\hline Period II & $17 \pm 2^{\ddagger}$ & $61 \pm 6^{\ddagger}$ & $24 \pm 3^{\ddagger}$ & $50 \pm 4^{\ddagger}$ & $52 \pm 4$ \\
\hline Period III & $36 \pm 3^{\ddagger}$ & $119 \pm 7^{\ddagger}$ & $45 \pm 4^{\ddagger}$ & $96 \pm 5^{\ddagger}$ & $53 \pm 3^{\ddagger}$ \\
\hline Period IV & $89 \pm 8^{\ddagger}$ & $202 \pm 11^{\ddagger}$ & $104 \pm 9^{\ddagger}$ & $107 \pm 8^{\ddagger *}$ & $39 \pm 4$ \\
\hline
\end{tabular}

The average concentration of insulin entering the liver $\left(I N S_{\text {ave }}\right)$, and the hepatic fractional extraction of insulin measured during periods I-IV of protocols 1 and 2 . Values are means \pm SEM for seven dogs. ${ }^{*}$ Significantly different from corresponding period of $P_{\mathrm{c}}(P<0.05)$; ${ }^{\ddagger}$ significantly different from period I value $(P<0.05)$.

corresponding periods in the two groups $(80 \pm 10,79 \pm 7,75 \pm 6$, and $68 \pm 5$ in periods I-IV of $P_{\mathrm{e}}$ and $70 \pm 8,72 \pm 4,68 \pm 5$, and $65 \pm 6 \mathrm{pg} / \mathrm{ml}$ in the corresponding periods of $P_{0}$ ).

The peripheral, portal and total glucose infusion rates used during the three test periods of protocols 1 and 2 are listed in Table III. Total glucose infusion rates were similar in the corresponding periods of the two groups.

Blood glucoses, hepatic blood flows, and hepatic glucose loads. The average concentrations of glucose entering the liver during the three test periods in the two groups were similar (Fig. 1: $176 \pm 8,171 \pm 7$, and $176 \pm 6 \mathrm{mg} / \mathrm{dl}$ in $P_{e}$; and $168 \pm 6$, $175 \pm 6$, and $175 \pm 5 \mathrm{mg} / \mathrm{dl}$ in $P_{0}$ ). Hepatic blood flow (Fig. $1 c$ ) increased slightly by the end of the study rising from control values of $39 \pm 4$ and $43 \pm 3 \mathrm{ml} / \mathrm{kg}$ per $\mathrm{min}$ in $P_{\mathrm{e}}$ and $P_{0}$, respectively, to $39 \pm 4,41 \pm 4$, and $46 \pm 4 \mathrm{ml} / \mathrm{kg}$ per $\mathrm{min}$ in the three test periods of $P_{\mathrm{e}}$ and $42 \pm 3,44 \pm 3$, and $47 \pm 3 \mathrm{ml} / \mathrm{kg}$ per $\mathrm{min}$ in the corresponding periods of $P_{0}$.

Table II. Arterial and Portal Glucagon Concentrations and Average Concentration of Glucagon

Entering the Liver (GGN ave)

\begin{tabular}{llccc}
\hline & \multicolumn{4}{c}{ Glucagon concentration } \\
\cline { 2 - 5 } & Period I & Period II & Period III & Period IV \\
\hline & \multicolumn{5}{c}{$p g / m l$} \\
Protocol 1 $\left(P_{\mathrm{e}}\right)$ & \multicolumn{4}{c}{} \\
$\quad$ Artery & $60 \pm 7$ & $58 \pm 6$ & $56 \pm 8$ & $54 \pm 8^{*}$ \\
Portal Vein & $86 \pm 12$ & $86 \pm 7$ & $81 \pm 5$ & $73 \pm 5$ \\
GGN & $80 \pm 10$ & $79 \pm 7$ & $75 \pm 6$ & $68 \pm 5$ \\
Protocol 2 $\left(P_{0}\right)$ & & & & \\
Artery & $61 \pm 9$ & $56 \pm 7$ & $48 \pm 6^{*}$ & $47 \pm 6$ \\
Portal Vein & $73 \pm 8$ & $78 \pm 5$ & $75 \pm 4$ & $72 \pm 6$ \\
GGN $_{\text {ave }}$ & $70 \pm 8$ & $72 \pm 4$ & $68 \pm 5$ & $65 \pm 6$ \\
\hline
\end{tabular}

Measurements were taken during periods I-IV of protocols 1 and 2. Values are means \pm SEM for seven dogs. ${ }^{*}$ Significantly different from control period value $(P<0.05)$.
Table III. Rates of Glucose Infusion into a Peripheral Vein and the Portal Vein, and the Total Glucose Infusion Rates Used in Periods I-IV of Protocols 1 and 2

\begin{tabular}{lccc}
\hline & Peripheral & Portal & Total \\
\hline & & $m g / k g$ per min & \\
Protocol 1 $\left(P_{\mathrm{e}}\right)$ & & & \\
Period I & None infused & None infused & None infused \\
Period II & $4.85 \pm 0.73$ & None infused & $4.85 \pm 0.73$ \\
Period III & $10.58 \pm 1.20$ & None infused & $10.58 \pm 1.20$ \\
Period IV & $25.31 \pm 2.88$ & None infused & $25.31 \pm 2.88$ \\
Protocol 2 $\left(P_{0}\right)$ & & & \\
Period I & None infused & None infused & None infused \\
Period II & None infused & $4.49 \pm 0.47$ & $4.49 \pm 0.47$ \\
Period III & $8.13 \pm 1.44$ & $4.57 \pm 0.46$ & $12.70 \pm 1.58$ \\
Period IV & $21.33 \pm 2.46$ & $4.57 \pm 0.46$ & $25.89 \pm 2.44$ \\
& & & \\
\hline
\end{tabular}

Values are means \pm SEM for seven dogs.

The load of glucose reaching the liver (Fig. $2 a$ ) was similar in periods II and III of $P_{e}(68.7 \pm 7.3$ and $70.2 \pm 7.3 \mathrm{mg} / \mathrm{kg}$ per min, respectively) but rose slightly during period IV $(80.1 \pm 7.2$ $\mathrm{mg} / \mathrm{kg}$ per $\mathrm{min}$ ) due to the increase in hepatic blood flow. Such was also the case in the three test periods of $P_{0}(70.2 \pm 4.6$, $75.3 \pm 6.1$, and $85.2 \pm 6.7 \mathrm{mg} / \mathrm{kg}$ per min in periods II-IV, respectively). The hepatic glucose loads in the corresponding periods of $P_{\mathrm{e}}$ and $P_{0}$ were not significantly different.

Net hepatic glucose balance and hepatic fractional extraction of glucose. The liver switched from net production of glucose in the control periods of $P_{\mathrm{e}}$ and $P_{0}(2.01 \pm 0.21$ and $2.30 \pm 0.14 \mathrm{mg} / \mathrm{kg}$ per min, respectively) to net consumption of glucose in period II as the load of glucose to the liver and the plasma insulin level were raised (Fig. $2 b$ ). Net hepatic glucose

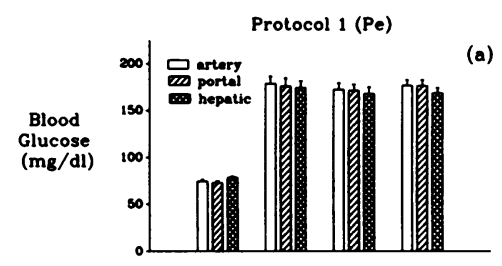

(a)

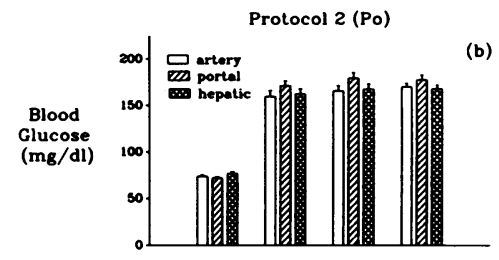

Figure 1. Blood glucose levels in the artery, portal vein, and hepatic

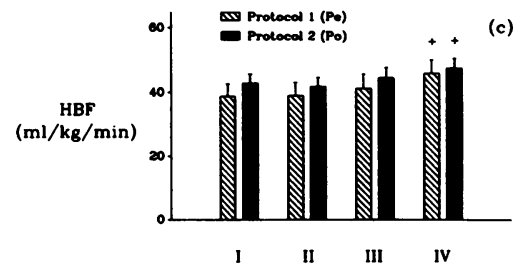
vein and total $\mathrm{HBF}$ in the four periods of protocols 1 and 2 . Values are means \pm SEM for seven dogs. +Significantly different from control period value $(P<0.05)$ 

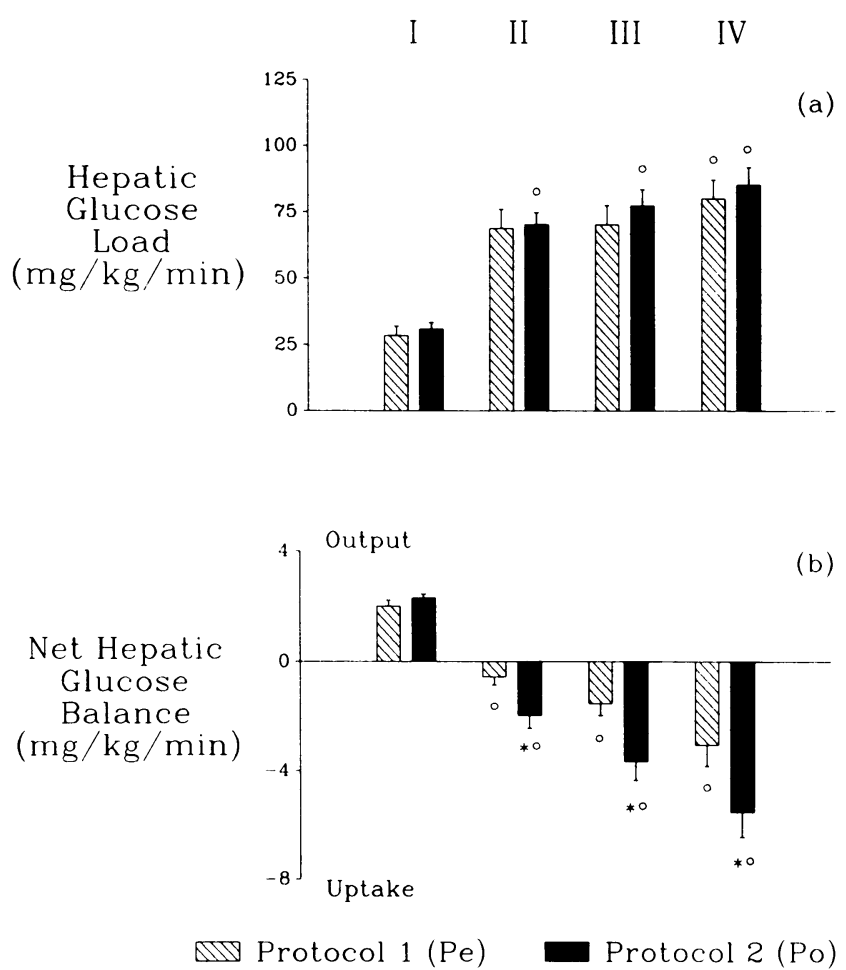

Figure 2. Hepatic glucose loads and net hepatic glucose balances during periods I-IV of protocols 1 and 2 . Values are means \pm SEM for seven dogs. *Significantly different from value in corresponding period of $P_{\mathrm{c}}(P<0.05)$; ${ }^{\circ}$ significantly different from the other two test period values $(P<0.05)$.

uptake increased from $0.55 \pm 0.30 \mathrm{mg} / \mathrm{kg}$ per min at the lowest insulin infusion rate in $P_{\mathrm{e}}$ to $1.52 \pm 0.44$ and then to $3.04 \pm 0.79$ $\mathrm{mg} / \mathrm{kg}$ per min as the insulin infusion rate was elevated. When a portion of the glucose load was delivered portally, net hepatic glucose uptake was two- to threefold greater $(1.96 \pm 0.48$, $3.67 \pm 0.68$, and $5.52 \pm 0.92 \mathrm{mg} / \mathrm{kg}$ per min in periods II-IV, respectively) than when the sugar was infused by the peripheral route only.

Fig. 3 illustrates the dependence of net hepatic glucose uptake on the arterial plasma insulin levels. In both protocols net hepatic glucose uptake demonstrated a dose dependence on insulin which appeared to be reaching saturation at the highest insulin dose employed. Delivery of a portion of the glucose load directly into the portal vein increased net glucose uptake by the liver significantly at all insulin doses examined.

To decrease the influence that slight differences in the hepatic glucose load may have had on the results, the fractional extraction of glucose by the liver was also calculated. Fig. 4 depicts the relationship between hepatic fractional extraction of glucose and the arterial plasma insulin level. As was the case with net hepatic glucose uptake, hepatic fractional extraction of glucose demonstrated a dose dependence on insulin in both groups. Intraportal glucose delivery was again associated with a significant 1.6- to 3.1-fold elevation in hepatic fractional extraction of glucose by the liver.

Lactate concentrations, hepatic lactate metabolism, and net hepatic uptake of glucose equivalents. Arterial blood lactate levels (Table IV) rose throughout the course of the experiment from $0.35 \pm 0.02 \mathrm{mM}$ during the control period of $P_{\mathrm{e}}$ to $0.80 \pm 0.17,1.20 \pm 0.15$, and $1.77 \pm 0.18 \mathrm{mM}$ in periods II-IV,

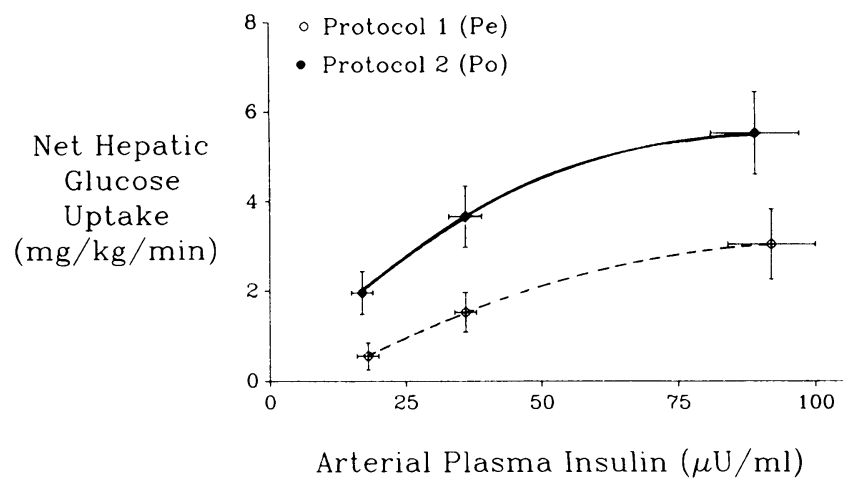

Figure 3. Relationship between net uptake of glucose by the liver $(\mathrm{mg} / \mathrm{kg}$ per $\mathrm{min})$ and the arterial insulin concentration. Values are means \pm SEM for seven dogs.

respectively. Arterial blood lactate levels followed a similar pattern in $P_{0}$ with levels rising from $0.38 \pm 0.04 \mathrm{mM}$ in the control period to $1.01 \pm 0.18,1.53 \pm 0.14$, and $2.12 \pm 0.17 \mathrm{mM}$ in the remaining three periods, respectively. Although test period values in $P_{0}$ tended to be higher than those in $P_{\mathrm{e}}$, the difference was significant only during period III.

The liver switched from being a net lactate consumer during the control period to a net producer of lactate during the remaining three periods of both protocols. Differences between the rates of hepatic lactate production in the two groups were not significant.

To examine the relative importance of hepatic lactate metabolism in the disposal of the glucose removed by the liver, the balance of glucose equivalents across the liver (NHLB + NHGB) was determined (Fig. 5). As with net hepatic glucose balance, net hepatic balance of glucose equivalents demonstrated a dose dependence on insulin, which was significantly altered in the presence of intraportal glucose delivery, showing that the differences in hepatic glucose uptake both within and between groups were not due to changes in hepatic lactate metabolism.

Peripheral glucose uptake and clearance. Peripheral glucose uptake in $P_{\mathrm{e}}$ rose throughout the experiment from $2.01 \pm 0.21$ $\mathrm{mg} / \mathrm{kg}$ per min in the control period to $4.30 \pm 0.58,9.06 \pm 1.29$, and $22.27 \pm 2.87 \mathrm{mg} / \mathrm{kg}$ per min in periods II-IV, respectively (Fig. $6 a$ ). Peripheral glucose uptake did not change significantly from the control period value during period II of $P_{0}$

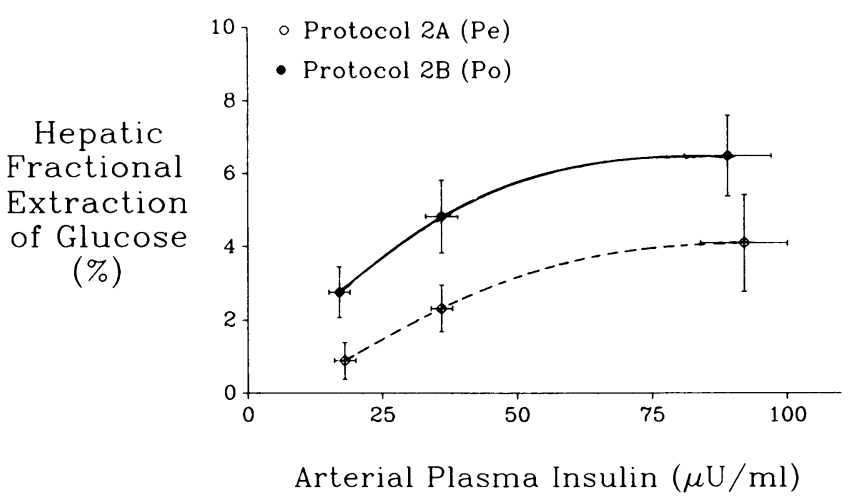

Figure 4. Relationship between hepatic fractional extraction of glucose (\%) and the arterial insulin concentration. Values are means \pm SEM for seven dogs. 
Table IV. Lactate Concentrations in the Artery, Portal Vein, and Hepatic Vein, and the Net Hepatic Lactate Balance during Periods I-IV of Protocols 1 and 2

\begin{tabular}{|c|c|c|c|c|}
\hline & \multicolumn{3}{|c|}{ Concentration } & \multirow[b]{2}{*}{ Net hepatic lactate balance* } \\
\hline & Artery & Portal & Hepatic & \\
\hline & & $m M$ & & $\mu \mathrm{mol} / \mathrm{kg} / \mathrm{min}$ \\
\hline \multicolumn{5}{|c|}{ Protocol $1\left(P_{\mathrm{e}}\right)$} \\
\hline Period I & $0.35 \pm 0.02$ & $0.43 \pm 0.03$ & $0.17 \pm 0.02$ & $-9.04 \pm 0.82$ \\
\hline Period II & $0.80 \pm 0.17^{\ddagger}$ & $0.87 \pm 0.18^{\ddagger}$ & $0.94 \pm 0.24^{\ddagger}$ & $2.89 \pm 2.57^{\ddagger}$ \\
\hline Period III & $1.20 \pm 0.15^{\ddagger}$ & $1.19 \pm 0.15^{\ddagger}$ & $1.35 \pm 0.21^{\ddagger}$ & $6.39 \pm 2.52^{\ddagger}$ \\
\hline Period IV & $1.77 \pm 0.18^{\ddagger}$ & $1.74 \pm 0.16^{\ddagger}$ & $1.86 \pm 0.20^{\ddagger}$ & $3.99 \pm 3.80^{\ddagger}$ \\
\hline \multicolumn{5}{|c|}{ Protocol $2\left(P_{0}\right)$} \\
\hline Period I & $0.38 \pm 0.04$ & $0.47 \pm 0.04$ & $0.20 \pm 0.02$ & $-10.18 \pm 0.56$ \\
\hline Period II & $1.01 \pm 0.18^{\ddagger}$ & $1.08 \pm 0.17^{\ddagger}$ & $1.18 \pm 0.25^{\ddagger}$ & $4.93 \pm 3.53^{\ddagger}$ \\
\hline Period III & $1.53 \pm 0.14^{\ddagger}$ & $1.48 \pm 0.15^{\ddagger}$ & $1.70 \pm 0.19^{\ddagger}$ & $8.73 \pm 2.19^{\ddagger}$ \\
\hline Period IV & $2.12 \pm 0.17^{\ddagger}$ & $2.04 \pm 0.16^{\ddagger}$ & $2.22 \pm 0.24^{\ddagger}$ & $7.99 \pm 4.45^{\ddagger}$ \\
\hline
\end{tabular}

Values are means \pm SEM for seven dogs. ${ }^{*}$ Positive values indicate hepatic lactate production; ${ }^{\ddagger}$ significantly different from control period value $(P<0.05)$.

$(2.30 \pm 0.14$ and $2.53 \pm 0.42 \mathrm{mg} / \mathrm{kg}$ per $\mathrm{min}$ in periods I and II, respectively), but rose to $9.04 \pm 1.98 \mathrm{mg} / \mathrm{kg}$ per min during period III and further to $20.37 \pm 2.77 \mathrm{mg} / \mathrm{kg}$ per min in period IV. Although peripheral glucose uptake was significantly $(P$ $<0.05$ ) greater during period II of $P_{\mathrm{e}}$ than in $P_{0}$, corresponding values in the remaining two test periods were not significantly different.

Peripheral glucose clearance in $P_{\mathrm{e}}$ changed from $2.02 \pm 0.20$ $\mathrm{ml} / \mathrm{kg}$ per $\mathrm{min}$ in the control period to $1.63 \pm 0.16 \mathrm{ml} / \mathrm{kg}$ per $\mathrm{min}$ in period II and then rose to $3.70 \pm 0.61$ and $9.06 \pm 1.18$ $\mathrm{ml} / \mathrm{kg}$ per min in periods III and IV, respectively. Peripheral glucose clearance in $P_{0}$ dropped significantly from $2.28 \pm 0.15$ $\mathrm{ml} / \mathrm{kg}$ per $\mathrm{min}$ in the control period to $1.12 \pm 0.20 \mathrm{ml} / \mathrm{kg}$ per min during period II and then increased to $3.94 \pm 0.86$ and then to $8.86 \pm 1.18 \mathrm{ml} / \mathrm{kg}$ per min in periods III and IV, respectively. Corresponding values between the two groups differed significantly only during period II.

\section{Discussion}

Although the importance of insulin in the promotion of net glucose uptake by the liver has been established (9-17), the

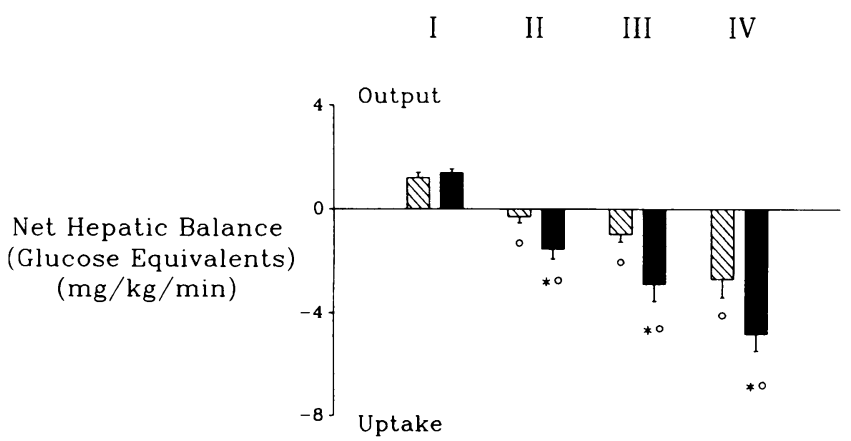

Figure 5. Net balance of glucose equivalents across the liver during periods I-IV of protocols $1, P_{\mathrm{e}}(\mathbb{\square})$; and $2, P_{0}(\varpi)$. Values are means \pm SEM for seven dogs. ${ }^{*}$ Significantly different from corresponding period of $P_{\mathrm{e}}(P<0.05)$; ${ }^{\circ}$ significantly different from the other two test period values $(P<0.05)$. precise relationship between insulin and net hepatic glucose uptake (NHGU) has been difficult to define due to the difficulty in obtaining portal and hepatic vein blood samples. In addition, the influence of intraportal glucose delivery on the relationship between insulin and liver glucose uptake has yet to be addressed. The results of these experiments define, over the physiological range of arterial insulin levels ( 18 to $90 \mu \mathrm{U} / \mathrm{ml}$ ), the relationship between the hormone and NHGU. In addition, they show that in the presence of portal glucose delivery NHGU is increased by two- to threefold, making the route of

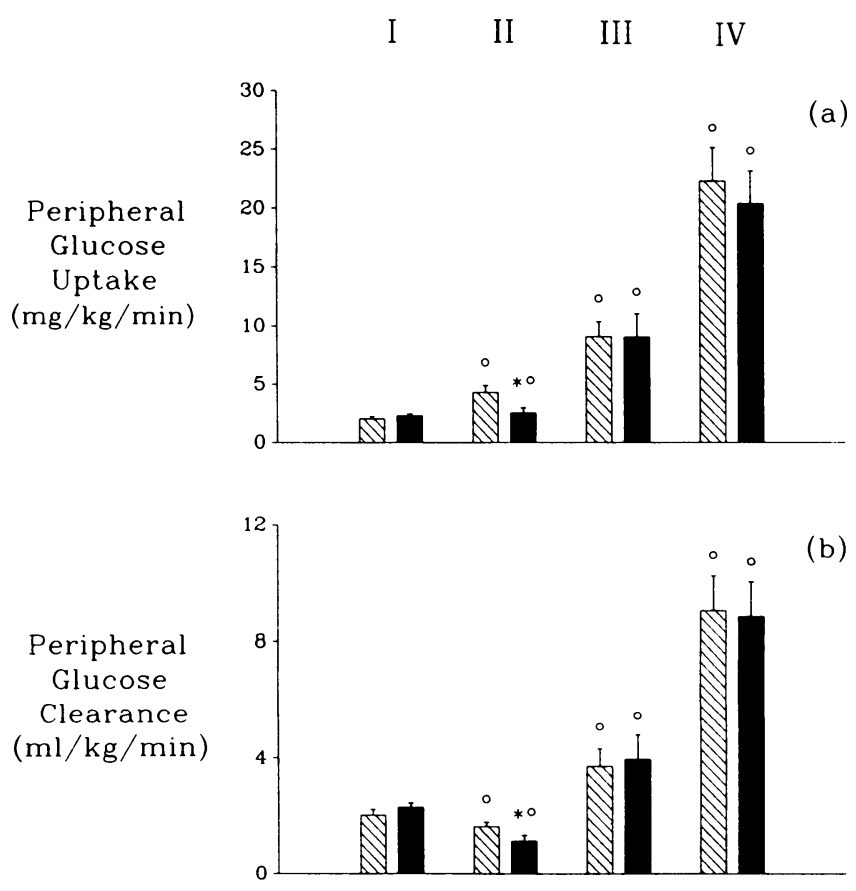

Figure 6. Peripheral glucose uptake and peripheral glucose clearance in periods I-IV of protocols $1, P_{\mathrm{e}}(\square)$; and $2, P_{0}(\square)$. Values are means \pm SEM for seven dogs. *Significantly different from corresponding period of $P_{\mathrm{e}}(P<0.05)$; ${ }^{\circ}$ significantly different from the other two test period values $(P<0.05)$. 
glucose delivery of at least equal importance to insulin in promoting NHGU at insulin levels normally seen after feeding.

When peripheral glucose delivery was used to double the glucose load to the liver, NHGU increased from $0.55 \pm 0.30$ $\mathrm{mg} / \mathrm{kg}$ per min at the lowest inflowing insulin level $(51 \pm 2 \mu \mathrm{U} /$ $\mathrm{ml}$ ) to $3.04 \pm 0.79 \mathrm{mg} / \mathrm{kg}$ per min at the highest inflowing insulin concentration $(191 \pm 11 \mu \mathrm{U} / \mathrm{ml})$. When a portion of the infused glucose was given portally, but in such a way as to keep the total glucose load to the liver the same as when glucose was given peripherally, NHGU was increased (by 1.4 to $2.5 \mathrm{mg} / \mathrm{kg}$ per min) over that seen with peripheral glucose infusion at each insulin level.

The range over which insulin appeared to be exerting an effect on NHGU was similar to that observed by Rizza et al. (8) for the suppression of endogenous glucose production by insulin at basal glucose levels. Since these concentrations were well within the physiological range, it is apparent that insulin can play a very significant role in regulating the disposal of a glucose load not only through peripheral effects but also through an action at the liver. The saturation in NHGU that was approached at the highest inflowing insulin level may actually be more complete than is apparent, since the rise in blood flow that occurred caused the load of glucose reaching the liver to increase $\simeq 12 \%$ at the highest insulin dose. Had the load not increased net hepatic glucose uptake would have been somewhat reduced (31). The fact that saturation is approached at relatively low levels of insulin may explain, at least in part, why in the human experiments of DeFronzo et al. (5) and Ferrannini et al. (6), increasing the arterial insulin level above 55 $\mu \mathrm{U} / \mathrm{ml}$ did not cause a significant rise in net splanchnic glucose uptake.

Since NHGU can be significantly altered by changes in the hepatic glucose load (31; Myers, Biggers, Neal, and Cherrington, manuscript in preparation) the relationship between insulin and the hepatic fractional extraction of glucose (HFXE) was also examined. As with NHGU, HFXE demonstrated a dose dependence on insulin that was significantly altered by the presence of intraportal glucose delivery. Although this suggests that the relationships described above are real and not merely artifacts of slight differences in the hepatic glucose load, it should be noted that, because the line relating NHGU to the hepatic glucose load does not intersect the origin (Myers, Biggers, Neal, and Cherrington, manuscript in preparation) hepatic fractional extraction of glucose (NHGU + LOAD) is also affected by changes in the hepatic glucose load. Still, adjusting HFXE to correct for load differences resulted in a relationship similar to that depicted in Fig. 4. (When all loads were set equal to 70 $\mathrm{mg} / \mathrm{kg}$ per $\mathrm{min}$, HFXE was $0.9,2.3$, and $3.4 \%$ in periods II-IV of $P_{\mathrm{e}}$ and $2.8,4.6$, and $5.9 \%$ in the corresponding periods of $P_{0}$.) Thus, it is apparent that slight differences in the hepatic glucose load were not responsible for the changes in NHGU observed in this study.

Because technical problems associated with the infusion of a substance directly into the portal vein could have had an impact on the results of these studies, great care was taken to examine and eliminate potential technical errors wherever possible. Adequate mixing of the intraportal glucose infusate with the blood perfusing the liver was of great concern, for systematic errors in mixing, while not affecting NHGU calculated during peripheral glucose delivery, could have caused errors in the calculation of NHGU during intraportal glucose delivery. The excellent recovery of PAH in the hepatic vein in these experiments $(100 \pm 11 \%)$ indicates that improper mixing was not a problem. Mixing errors when they did occur were random such that the mean data gave an accurate representation of the liver's response.

To circumvent the use of the portal glucose value in the calculation of NHGB, an "indirect" method of calculating net hepatic glucose balance was used as described previously (16, 17). Comparison of this indirect method and the more commonly used direct method of calculation of NHGU (Table V) shows that the absolute values obtained from the two approaches were not significantly different. The conclusions drawn regarding both the dose response curve and the "portal" signal were unaffected by the method of calculation chosen.

Although the dye extraction technique is a simple, accurate method of assessing hepatic blood flow, the use of this technique in these experiments introduced two additional potential sources of error: $(a)$ the assumption of the distribution of hepatic blood flow between the hepatic artery and the portal vein and $(b)$ the less than ideal steady-state plasma levels of the dye in the final period of the study potentially causing an overestimation of hepatic blood flow in this period. The use of a second method of blood flow measurement, the synchronized, pulsed Doppler method, eliminated both of these problems. Table VI illustrates the average hepatic blood flows, blood flow distributions, and net hepatic glucose balances measured using both blood flow methods in the four dogs in which both indocyanine-green- and Doppler-determined blood flow were available. From these data it is evident that similar results were obtained and similar conclusions were drawn when either indocyanine-green- or Doppler-determined blood flows were used in the calculation of NHGU. It is interesting to note that the Doppler-determined flows were $\simeq 15 \%$ lower than dye-determined flows in periods I through III of both protocols. In period IV, however, the Doppler data suggest that blood flow rose only slightly $(\simeq 10 \%)$ while the dye method indicated a much larger rise $(\simeq 25 \%)$. Thus in period IV the two methods were quite divergent. It seems likely that the dye method becomes inaccurate as the duration of the study extends beyond $300 \mathrm{~min}$, probably due to saturation of the dye removal mechanisms (25).

Table V. Comparison of Direct and Indirect Calculations of Net Hepatic Glucose Balance

\begin{tabular}{lcc}
\hline & Direct & Indirect \\
\hline \multicolumn{3}{c}{$m g / k g$ per min } \\
Protocol I $\left(P_{\mathrm{e}}\right)$ & \multicolumn{3}{c}{} \\
Period I & $2.01 \pm 0.21$ & $2.01 \pm 0.21$ \\
Period II & $-0.66 \pm 0.31^{\ddagger}$ & $-0.55 \pm 0.30^{\ddagger}$ \\
Period III & $-1.82 \pm 0.36^{\ddagger}$ & $-1.52 \pm 0.44^{\ddagger}$ \\
Period IV & $-3.32 \pm 0.68^{\ddagger}$ & $-3.04 \pm 0.79^{\ddagger}$ \\
Protocol 2 $\left(P_{0}\right)$ & & \\
Period I & $2.30 \pm 0.14$ & $2.30 \pm 0.14$ \\
Period II & $-1.77 \pm 0.58^{* \ddagger}$ & $-1.96 \pm 0.48^{* \ddagger}$ \\
Period III & $-3.98 \pm 0.45^{*}$ & $-3.67 \pm 0.68^{* \ddagger}$ \\
Period IV & $-4.49 \pm 0.74^{*}$ & $-5.52 \pm 0.92^{* \ddagger}$
\end{tabular}

Values are means \pm SEM for seven dogs.

* Significantly different from corresponding period of $P_{\mathrm{e}}(P<0.05)$;

‡ significantly different from other two test period values $(P<0.05)$. 
Table VI. Indocyanine-Green- and Doppler-determined Hepatic Blood Flows, Doppler-determined Distributions of Hepatic Blood Flow Between the Artery, and the Portal Vein, and Net Hepatic Glucose Balances (Indirect Method of Calculation)

\begin{tabular}{|c|c|c|c|c|c|c|}
\hline & \multicolumn{2}{|c|}{$\mathrm{HBF}$} & \multicolumn{2}{|c|}{$\begin{array}{l}\text { Doppler-determined hepatic } \\
\text { blood flow distribution }\end{array}$} & \multicolumn{2}{|c|}{ NHGB } \\
\hline & $\begin{array}{l}\text { Indocyanine } \\
\text { green }\end{array}$ & Doppler & Artery & $\begin{array}{l}\text { Portal } \\
\text { vein }\end{array}$ & $\begin{array}{l}\text { Indocyanine } \\
\text { green }\end{array}$ & Doppler \\
\hline & \multicolumn{2}{|c|}{$\mathrm{ml} / \mathrm{kg} / \mathrm{min}$} & \multicolumn{2}{|c|}{$\%$} & \multicolumn{2}{|c|}{$m g / k g / m i n$} \\
\hline \multicolumn{7}{|c|}{ Protocol $1\left(P_{\mathrm{e}}\right)$} \\
\hline Period I & $44.4 \pm 3.4$ & $35.6 \pm 5.1$ & $18 \pm 2$ & $82 \pm 2$ & $2.19 \pm 0.38$ & $1.80 \pm 0.36$ \\
\hline Period II & $43.4 \pm 0.7$ & $35.7 \pm 3.4$ & $23 \pm 2$ & $77 \pm 2$ & $-0.77 \pm 0.43$ & $-0.63 \pm 0.39$ \\
\hline Period III & $48.7 \pm 1.8$ & $37.9 \pm 2.3$ & $26 \pm 3$ & $75 \pm 3$ & $-2.70 \pm 0.83$ & $-2.03 \pm 0.65$ \\
\hline Period IV & $57.6 \pm 5.4$ & $41.8 \pm 2.5$ & $28 \pm 4$ & $72 \pm 4$ & $-3.54 \pm 0.64$ & $-2.66 \pm 0.68$ \\
\hline \multicolumn{7}{|c|}{ Protocol $2\left(P_{0}\right)$} \\
\hline Period I & $43.5 \pm 3.2$ & $41.4 \pm 3.3$ & $18 \pm 4$ & $82 \pm 4$ & $2.37 \pm 0.27$ & $2.32 \pm 0.28$ \\
\hline Period II & $43.9 \pm 2.1$ & $39.8 \pm 2.6$ & $24 \pm 4$ & $76 \pm 4$ & $-2.47 \pm 0.54^{*}$ & $-2.69 \pm 0.28^{*}$ \\
\hline Period III & $49.3 \pm 7.1$ & $41.4 \pm 3.6$ & $25 \pm 4$ & $75 \pm 4$ & $-4.32 \pm 1.16$ & $-4.44 \pm 0.72^{*}$ \\
\hline Period IV & $62.9 \pm 12.7$ & $45.8 \pm 4.6$ & $26 \pm 5$ & $74 \pm 5$ & $-6.14 \pm 1.22^{*}$ & $-5.96 \pm 1.03 *$ \\
\hline
\end{tabular}

Calculations were done using indocyanine-green- and Doppler-determined hepatic blood flow in periods I-IV of protocols 1 and 2. Values are means \pm SEM for the four dogs in which blood flow was measured simultaneously with dye and Doppler. * Significantly different from corresponding period of $P_{\mathrm{e}}(P<0.05)$.

While the use of the Doppler method of blood flow measurement circumvented the problems associated with the dye extraction technique, it also introduced another potential source of error. Because many of the hepatic nerves can be found in the tissue surrounding both the hepatic artery and the portal vein, the possibility existed that nerve damage could have occurred during the implantation of the flow probes. To ensure that accidental damage to the hepatic nerves had not occurred, norepinephrine levels were measured in liver tissue taken from five animals in which Doppler flow probes were used. Tissue norepinephrine levels in all liver lobes were similar to those in tissue taken from three control dogs (levels in the left posterior, left central, left lateral, right central, right lateral, caudate, and quadrate lobes in these animals were $514,377,308,416,439$, 397 , and $372 \mathrm{ng} / \mathrm{g}$ tissue, respectively, as compared with 500 , $359,492,343,357$, and $392 \mathrm{ng} / \mathrm{g}$ tissue in the same seven lobes of control dogs), indicating that little, if any, nerve damage had occurred.

The simplest way to calculate NHGB is to multiply the whole blood glucose difference across the liver times HBF. Given the need to deproteinize the blood sample and the analytical error in measuring glucose on the autoanalyzer, we attempted to additionally calculate NHGB using HBF and plasma glucose values corrected to whole blood glucose values using blood/plasma glucose ratios determined in each experiment. Table VII shows that, in fact, this difference in approach had little effect on the data obtained, and made no difference to the conclusions drawn regarding insulin's ability to stimulate glucose uptake by the liver or the ability of the "portal" signal to trigger additional hepatic glucose uptake.

Neither insulin nor intraportal glucose delivery resulted in significant changes in net hepatic lactate production. Thus, although the fate of glucose taken up by the liver was not specifically addressed in this study, it is clear that the changes in hepatic glucose uptake caused by insulin and intraportal glucose delivery could not be explained by changes in net hepatic lactate metabolism (see Fig. 5). It is likely that alterations in hepatic glycogen metabolism similar to those observed in other studies of hepatic insulin action (32-37) were involved in the increases in net hepatic glucose uptake observed here. That is to say that insulin has a significant affect on glycogen deposition in the liver, as does the "portal" signal.

In addition to the effects of insulin and intraportal glucose delivery on hepatic glucose metabolism, effects of these factors on peripheral glucose metabolism were also explored. In general, peripheral glucose uptake increased in parallel with the increase in the arterial insulin level in both groups. Since the small rise in the arterial insulin concentration at the lowest insulin infusion rate would have resulted in only a $10 \%$ increase in the glucose clearance rate $(8)$, while the simultaneous

Table VII. Comparison of Net Hepatic Glucose Balance Calculated Using Blood Glucose Values or Plasma Glucose Values Corrected to Blood Glucose Values Using the Blood/ Plasma Glucose Ratio (see Methods)

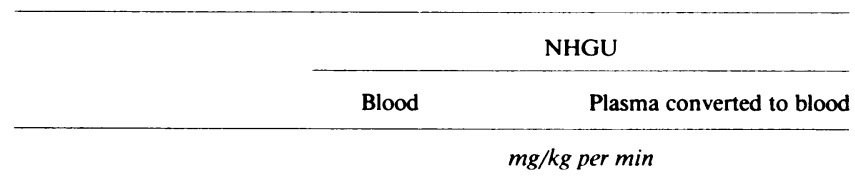

Protocol $1\left(P_{\mathrm{e}}\right)$

Period I

Period II

$1.99 \pm 0.39$

$2.01 \pm 0.21$

Period III

$-1.08 \pm 0.33$

$-0.55 \pm 0.30$

Period IV

Protocol $2\left(P_{0}\right)$

Period I

Period II

$-1.00 \pm 0.49$

$-1.53 \pm 0.44$

$-2.76 \pm 0.51$

$-3.04 \pm 0.77$

Period III

$1.86 \pm 0.21$

$-2.61 \pm 0.62 *$

$2.30 \pm 0.15$

Period IV

$-2.92 \pm 0.47^{*}$

$-1.96 \pm 0.48^{*}$

$-3.67 \pm 0.68^{*}$

$-5.52 \pm 0.92 *$

* Significantly $(P<0.05)$ greater than in corresponding period of $P_{\mathrm{e}}$. 
Table VIII. Total Glucose Infusion Rates, Hepatic and Peripheral Glucose Uptake, and Distribution of the Total Glucose Load between the Liver and the Periphery in Periods II-IV of Protocols 1 and 2

\begin{tabular}{|c|c|c|c|c|c|}
\hline & \multicolumn{2}{|c|}{ Glucose uptake } & \multirow{2}{*}{$\begin{array}{l}\text { Total glucose } \\
\text { infusion rate }\end{array}$} & \multicolumn{2}{|c|}{ Distribution of the glucose load } \\
\hline & Hepatic & Peripheral & & Hepatic & Peripheral \\
\hline & \multicolumn{2}{|c|}{$m g / k g / m i n$} & $m g / k g / m i n$ & \multicolumn{2}{|c|}{$\%$} \\
\hline \multicolumn{6}{|c|}{ Protocol $1\left(P_{\mathrm{e}}\right)$} \\
\hline Period II & $0.55 \pm 0.30$ & $4.30 \pm 0.58$ & $4.85 \pm 0.73$ & $10.1 \pm 5.2$ & $89.9 \pm 5.2$ \\
\hline Period III & $1.52 \pm 0.44$ & $9.06 \pm 1.29$ & $10.58 \pm 1.20$ & $15.7 \pm 4.4$ & $84.3 \pm 4.4$ \\
\hline Period IV & $3.04 \pm 0.79$ & $22.27 \pm 2.87$ & $25.31 \pm 2.88$ & $12.7 \pm 3.2$ & $87.3 \pm 3.2$ \\
\hline \multicolumn{6}{|c|}{ Protocol $2\left(P_{0}\right)$} \\
\hline Period II & $1.96 \pm 0.48$ & $2.53 \pm 0.42$ & $4.49 \pm 0.47$ & $43.4 \pm 10.4$ & $56.6 \pm 10.4$ \\
\hline Period III & $3.67 \pm 0.68$ & $9.04 \pm 1.98$ & $12.70 \pm 1.58$ & $33.2 \pm 8.7$ & $66.8 \pm 8.7$ \\
\hline Period IV & $5.52 \pm 0.92$ & $20.37 \pm 2.77$ & $25.89 \pm 2.44$ & $22.8 \pm 4.3$ & $77.2 \pm 4.3$ \\
\hline
\end{tabular}

Values are means \pm SEM for seven dogs.

elevation of the plasma glucose level would have resulted in a $20 \%$ decrease in the peripheral glucose clearance rate $(38,39)$, it is not unexpected that peripheral glucose clearance fell during the infusion of $0.6 \mathrm{mU} / \mathrm{kg}$ per min of insulin in both $P_{\mathrm{e}}$ and $P_{0}$. Thereafter, the subsequent rises in the arterial insulin levels resulted in dose-dependent increases in the peripheral glucose clearance rate. Although intraportal glucose delivery did not appear to alter peripheral glucose clearance at either of the two higher insulin doses used, the decrease in glucose clearance at the lowest insulin dose suggests that the factor associated with intraportal glucose delivery may simultaneously be exerting an inhibitory effect on peripheral glucose metabolism. Similar findings have been reported by Lautt (40) and Adkins et al. (16) and have led the latter investigators to suggest that this coordination of the response is an indication that either a neural or a humoral factor is involved.

Overall, the increase in hepatic glucose uptake (and, at the lowest step, the decrease in peripheral glucose uptake) during intraportal glucose delivery resulted in a greater contribution by the liver to the disposal of the total glucose load (Table VIII). During absorption of an oral glucose load, this phenomenon may be playing an important physiological role, facilitating the repletion of hepatic glycogen stores from the ingested glucose and contributing to the overall glucose tolerance of an individual. It should be noted that while intraportal glucose delivery enhanced the contribution of the liver to the disposal of the glucose load, nonhepatic tissues were still responsible for disposal of the majority of the glucose infused under all circumstances. These observations are consistent with findings in man and dog after the administration of an oral or intravenous glucose load $(5,6,9,10,14,16,17,42-44)$.

Intuitively, one would have expected the glucose infusion rate to have been higher during portal glucose delivery to account for the increase in hepatic glucose uptake. In these experiments, however, there was virtually no difference in the total glucose infusion rate between the two protocols. This apparent discrepancy can be explained by the decrease in peripheral glucose uptake during portal glucose delivery (Table VIII) caused, at least in part, by the difference in the glucose levels between the two studies. To maintain equivalent hepatic glucose loads, the arterial glucose level in the portal infusion studies was maintained at a level significantly lower than that in the peripheral glucose studies (a plasma glucose difference of $\sim 20-25$ $\mathrm{mg} / \mathrm{dl})$. Because the glucose level per se can effect peripheral glucose uptake (38), if net hepatic glucose uptake had been the same in both protocols, the portal infusion protocol should have had significantly lower glucose infusion rates than the peripheral infusion protocol. That the glucose infusion rates are the same adds further support for the observation that intraportal glucose delivery enhances hepatic glucose uptake.

Although the importance of the role of intraportal glucose delivery in the regulation of net hepatic glucose uptake has been demonstrated by this and other studies $(5,6,10,15-17$, $31,41)$, the mechanism by which intraportal glucose delivery increases hepatic glucose uptake has not yet been defined. It now seems clear that a "gut" factor, such as the one proposed by DeFronzo et al. (5), is not involved $(10,15,42)$. Attempts to implicate a humoral factor in this phenomenon have also failed (45). The most likely explanation thus far appears to involve the central nervous system. Reports from several different investigators (45-53) support the idea that the parasympathetic nervous system may be playing an important role in this phenomenon. In addition, in a recent report from this laboratory (54), it was noted that a nearly complete denervation of the liver caused the loss of the effects of intraportal glucose delivery on NHGU in the dog, suggesting that the effects of intraportal glucose delivery are neurally mediated. Still, as with the fate of glucose removed by the liver, further investigation is needed to determine the exact mechanism by which intraportal glucose delivery exerts its effects.

In summary, the results of the present experiments indicate that net hepatic glucose uptake is directly dependent upon the plasma insulin level. This dependence is significantly altered in the presence of portal glucose delivery, with the route of glucose delivery being of at least equal importance to insulin in the determination of net hepatic glucose uptake at insulin levels normally observed after feeding.

\section{Acknowledgments}

The authors gratefully acknowledge the excellent technical assistance of R. Keith Carr and secretarial assistance of Patsy Raymer. This work was supported by National Institutes of Health (NIH) grant R01-AM18243-12 and Diabetes Research and Training Center NIH grant P60DK-20593-10. 


\section{References}

1. Bishop, J. S., R. Steele, N. Altszuler, A. Dunn, C. Bjerknes, and R. C. DeBodo. 1965. Effects of insulin on liver glycogen synthesis and breakdown in the dog. Am. J. Physiol. 208:307-316.

2. Steele, R., J. S. Bishop, A. Dunn, N. Altszuler, I. Rathgeb, and R. C. de Bodo. 1965. Inhibition by insulin of hepatic glucose production in the normal dog. Am. J. Physiol. 208:301-306.

3. Wahren, J., P. Felig, E. Cerasi, and R. Luft. 1972. Splanchnic and peripheral glucose and amino acid metabolism in diabetes mellitus. J. Clin. Invest. 51:1870-1878.

4. Chiasson, J. L., J. E. Liljenquist, F. E. Finger, and W. W. Lacy. 1976. Differential sensitivity of glycogenolysis and gluconeogenesis to insulin infusions in dogs. Diabetes. 25:283-291.

5. DeFronzo, R. A., E. Ferrannini, R. Hendler, J. Wahren, and P. Felig. 1978. Influence of hyperinsulinemia, hyperglycemia, and the route of glucose administration on splanchnic glucose exchange. Proc. Natl. Acad. Sci. USA. 75:51735177 .

6. Ferrannini, E., J. Wahren, P. Felig, and R. DeFronzo. 1980. The role of fractional glucose extraction in the regulation of splanchnic glucose metabolism in normal and diabetic man. Metabolism. 29:28-35.

7. DeFronzo, R. A., E. Jacot, E. Jequier, E. Maeder, J. Wahren, and J. P. Felber. 1981. The effect of insulin on the disposal of intravenous glucose: results from indirect calorimetry and hepatic and femoral venous catheterization. Diabetes. 30:1000-1007.

8. Rizza, R. A., L. J. Mandarino, and J. E. Gerich. 1981. Dose-response characteristics for effects of insulin on production and utilization of glucose in man. Am. J. Physiol. 240:E630-E639.

9. DeFronzo, R. A., E. Ferrannini, R. Hendler, P. Felig, and F. Wahren. 1983. Regulation of splanchnic and peripheral glucose uptake by insulin and hyperglycemia in man. Diabetes. 32:35-45.

10. Barrett, E. J., E. Ferrannini, R. Gusberg, S. Bevilacqua, and R. A. DeFronzo. 1985. Hepatic and extrahepatic splanchnic glucose metabolism in the postabsorptive and glucose fed dog. Metabolism. 34:410-420.

11. Shulman, G. I., J. E. Liljenquist, P. E. Williams, W. W. Lacy, and A. D. Cherrington. 1978. Glucose disposal during insulinopenia in somatostatintreated dogs: The roles of glucose and glucagon. J. Clin. Invest. 62:487-491.

12. Liljenquist, J. E., G. L. Mueller, A. D. Cherrington, J. M. Perry, and D. Rabinowitz. 1979. Hyperglycemia per se (insulin and glucagon withdrawn) can inhibit hepatic glucose production in man. J. Clin. Endocrin. Metab. 48:171-175.

13. Cherrington, A. D., P. E. Williams, N. Abou-Mourad, W. W. Lacy, K. E. Steiner, and J. E. Liljenquist. 1982. Insulin as a mediator of hepatic glucose uptake in the conscious dog. Am. J. Physiol. 242:E97-E101.

14. Saccà, L., M. Cicala, B. Trimarco, B. Ungaro, and C. Vigorito. 1982. Differential effects of insulin on splanchnic and peripheral glucose disposal after an intravenous glucose load in man. J. Clin. Invest. 70:117-126.

15. Ishida, T., Z. Chap, J. Chou, R. Lewis, C. Hartley, M. Entman, and J. B. Field. 1983. Differential effects of oral, peripheral intravenous, and intraportal glucose on hepatic glucose uptake and insulin and glucagon extraction in conscious dogs. J. Clin. Invest. 72:590-601.

16. Adkins, B. A., S. R. Myers, G. K. Hendrick, R. W. Stevenson, P. E. Williams, and A. D. Cherrington. 1987. Importance of the route of intravenous glucose delivery to hepatic glucose balance in the conscious dog. J. Clin. Invest. 79:557-565.

17. Adkins-Marshall, B. A., S. R. Myers, G. K. Hendrick, P. E. Williams, K. Triebwasser, B. Floyd, and A. D. Cherrington. 1990. Interaction between insulin and glucose delivery route in regulation of net hepatic glucose uptake in conscious dogs. Diabetes. 39:87-95.

18. Chiasson, J. L., J. E. Liljenquist, B. C. Sinclair-Smith, and W. W. Lacy. 1975. Gluconeogenesis from alanine in normal post-absorptive man: intrahepatic stimulatory effect of glucagon. Diabetes. 24:574-584.

19. Goresky, C. A.. C. G. Back, and B. E. Nadeau. 1975. Red cell carriage of label: its limiting effect on the exchange of materials in the liver. Circ. Res. 36:328-351.

20. Kadish, A. H., R. L. Little, and J. C. Sternberg. 1968. A new and rapid method for the determination of glucose by measurement of rate of oxygen consumption. Clin. Chem. 14:116-131.

21. Lloyd, B., J. Burrin, P. Smythe, and K. G. M. M. Alberti. 1978. Enzymic fluorometric continuous-flow assays for blood glucose, lactate, pyruvate, alanine, glycerol, and 3-hydroxybutyrate. Clin. Chem. 24:1724-1729.

22. Brun, C. 1951. A rapid method for the determination of para-aminohippuric acid in kidney function tests. J. Lab. Clin. Med. 37:955-958.

23. Morgan, C. R., and A. L. Lazarow. 1963. Immunoassay of insulin: two antibody system. Plasma insulin of normal, subdiabetic and diabetic rats. Diabetes. 12:115-126.

24. Aguilar-Parada, E., A. M. Eisentraut, and R. H. Unger. 1969. Pancreatic glucagon secretion in normal and diabetic subjects. Am. J. Med. Sci. 257:415419.

25. Leevy, C. M., C. L. Mendenhall, W. Lesko, and M. M. Howard. 1962. Estimation of hepatic blood flow with indocyanine green. J. Clin. Invest. 41:1169-1179.
26. Hartley, C. J., H. G. Hanley, R. M. Lewis, and J. S. Cole. 1978. Synchronized pulsed Doppler blood flow and ultrasonic dimension measurement in conscious dogs. Ultrasound Med. Biol. 4:99-110.

27. Ishida, T., R. M. Lewis, C. J. Hartley, M. L. Entman, and J. B. Field. 1983. Comparison of hepatic extraction of insulin and glucagon in conscious and anesthetized dogs. Endocrinology. 112:1098-1109.

28. Jacquez, J. A. 1984. Red blood cell as glucose carrier: significance for placental and cerebral glucose transfer. Am. J. Physiol. 246:R289-R298.

29. Greenway, C. V., and R. D. Stark. 1971. Hepatic vascular bed. Physiol. Rev. 51:23-65.

30. Snedecor, G. W., and W. G. Cochran. 1967. Statistical Methods. 6th ed. lowa State University Press, Ames, IA. 593 pp.

31. Myers, S. R., D. W. Biggers, and A. D. Cherrington. 1986. Dependence of net hepatic glucose uptake (NHGU) on the hepatic glucose load is enhanced by portal glucose delivery. Diabetes. 35:84A.

32. Witters, L. A., and J. Avruch. 1978. Insulin regulation of hepatic glycogen synthase and phosphorylase. Biochemistry. 17:406-410.

33. Schudt, C. 1979. Regulation of glycogen synthesis in rat-hepatocyte cultures by glucose, insulin and glucocorticoids. Eur. J. Biochem. 97:155-160.

34. Beynen, A. C., and M. J. H. Geelen. 1981. Control of glycogen metabolism by insulin in isolated hepatocytes. Horm. Metab. Res. 13:376-378.

35. Nyfeler, F., P. Fasel, and P. Walter. 1981. Short-term stimulation of net glycogen production by insulin in rat hepatocytes. Biochim. Biophys. Acta. 675:17-23.

36. Storer, G. B., D. L. Topping, and R. P. Trimble. 1981. Direct stimulation by glucose and insulin of glycogen synthesis in perfused rat liver. FEBS (Fed. Eur. Biol. Soc.) Lett. 136:135-137.

37. Kruszynska, Y. T., P. D. Home, and K. G. M. M. Alberti. 1986. In vivo regulation of liver and skeletal muscle glycogen synthase activity by glucose and insulin. Diabetes. 35:662-667.

38. Cherrington, A. D., P. E. Williams, and M. S. Harris. 1978. Relationship between the plasma glucose level and glucose uptake in the conscious dog. Metab olism. 27:787-791.

39. Best, J. D., G. J. Taborsky, Jr., J. B. Halter, and D. Porte, Jr. 1981. Glucose disposal is not proportional to plasma glucose level in man. Diabetes. 30:847850.

40. Lautt, W. W. 1980. Hepatic nerves: a review of their functions and effects. Can. J. Physiol. Pharm. 58:105-123.

41. Adkins, B. A., S. R. Myers, G. K. Hendrick, P. E. Williams, K. Triebwasser, B. Floyd, and A. D. Cherrington. 1985. Interaction between insulin and the route of intravenous glucose delivery in the regulation of net hepatic glucose uptake in the conscious dog. Diabetes Res. Clin. Pract. 1(Suppl): 10.

42. Bergman, R. N., J. R. Beir, and P. M. Hourigan. 1982. Intraportal glucose infusion matched to oral glucose absorption: lack of evidence for "Gut Factor" involvement in hepatic glucose storage. Diabetes. 31:27-35.

43. Abumrad, N. N., A. D. Cherrington, P. E. Williams, W. W. Lacy, and D. Rabin. 1982. Absorption and disposition of a glucose load in the conscious dog. Am. J. Physiol. 242:E398-E406.

44. Jackson, R. A., R. D. Roshania, M. I. Hawa, B. M. Sim, and L. DiSilvio 1986. Impact of glucose ingestion on hepatic and peripheral glucose metabolism in man: an analysis based on simultaneous use of the forearm and double isotope techniques. J. Clin. Endocrinol. Metab. 63:541-549.

45. Chap, Z., T. Ishida, J. Chou, R. Lewis, C. Hartley, M. Entman, and J. B. Field. 1985. Effects of atropine and gastric inhibitory polypeptide on hepatic glucose uptake and insulin extraction in conscious dogs. J. Clin. Invest. 76:11741181.

46. Shimazu, T. 1967. Glycogen synthetase activity in liver: Regulation by the autonomic nerves. Science (Wash. DC). 156:1256-1257.

47. Mondon, C. E., and S. D. Burton. 1971. Factors modifying carbohydrate metabolism and effect of insulin in perfused rat liver. Am. J. Physiol. 220:724734.

48. Ottolenghi, C., A. Caniato, and O. Barnabei. 1971. Effect of acetylcholine on glycogen formation and the activity of glycogen synthetase in isolated, perfused rat liver. Nature (Lond.). 229:420-422.

49. Shimazu, T. 1971. Regulation of glycogen metabolism in liver by the autonomic nervous system. V. Activation of glycogen synthetase by vagal stimulation. Biochim. Biophys. Acta. 252:28-38.

50. Shimazu, T., and T. Fujimoto. 1971. Regulation of glycogen metabolism in liver by the autonomic nervous system. IV. Neural control of glycogen biosynthesis. Biochim. Biophys. Acta. 252:18-27.

51. Akpan, J. O., R. Gardner, and S. R. Wagle. 1974. Studies on the effects of insulin and acetylcholine on activation of glycogen synthase and on glycogenesis in hepatocytes isolated from normal fed rats. Biochem. Biophys. Res. Commun 61:222-229.

52. Lautt, W. W., and C. Wong. 1978. Hepatic parasympathetic neural effect on glucose balance in the intact liver. Can. J. Physiol. Pharmacol. 56:679-682.

53. Niijima, A. 1985. Blood glucose levels modulate efferent activity in the vagal supply to the rat liver. J. Physiol. 364:105-112.

54. Adkins-Marshall, B. A., J. Asher, S. Myers, C. Connolly, G. Moore, D. Neal, P. Williams, and A. D. Cherrington. 1988. Involvement of the CNS in the response of the liver to portal glucose delivery. Diabetologia. 31:462a. (Abstr.) 